\title{
Posterior Cervical Spinal Cord Infarction following Thyrocervical Trunk Embolization
}

\author{
Jae Young An In Uk Song Woo Jun Kim Joong Seok Kim Yeong In Kim Kwang Soo Lee
}

Department of Neurology, College of Medicine, The Catholic University of Korea, Seoul, Korea

Dear Sir,

Spinal cord infarction is much less frequent than cerebral infarction, accounting for only $1 \%$ of all strokes and, furthermore, posterior spinal cord infarction is particularly rare [1-3]. Etiologies of spinal cord infarction are heterogeneous such as vertebral dissection, hypotension, atherosclerosis of vertebral arteries, cocaine misuse, fibrocartilaginous embolization, aortic aneurysmal repair, epidural anesthesia, vasculitis and prothrombin mutation [4]. We report the case of posterior cervical spinal cord infarction following thyrocervical trunk embolization for hemoptysis.

\section{Case}

A 30-year-old woman with previous bronchial tuberculosis was admitted with recurrent hemoptysis. Selective angiography showed that both bronchial arteries, right thyrocervical artery, left intercostal artery and left internal thoracic artery were hypertrophied along with abnormal parenchymal stain and systemic pulmonary shunt. These abnormal arteries were embolized with microcoils (Tornado, Cook) and polyvinyl alcohol particles (Contour; Boston Scientific, Cork, Ireland) (fig. 1a, b). Immediately after embolotherapy, the patient complained of numbness in the lower extremities. Neurological examination disclosed reduced sensation to all modalities below the T12 dermatome, which was more severely affected at vibration and proprioception testing. Muscle power in the muscles of the upper extremities was normal and in the
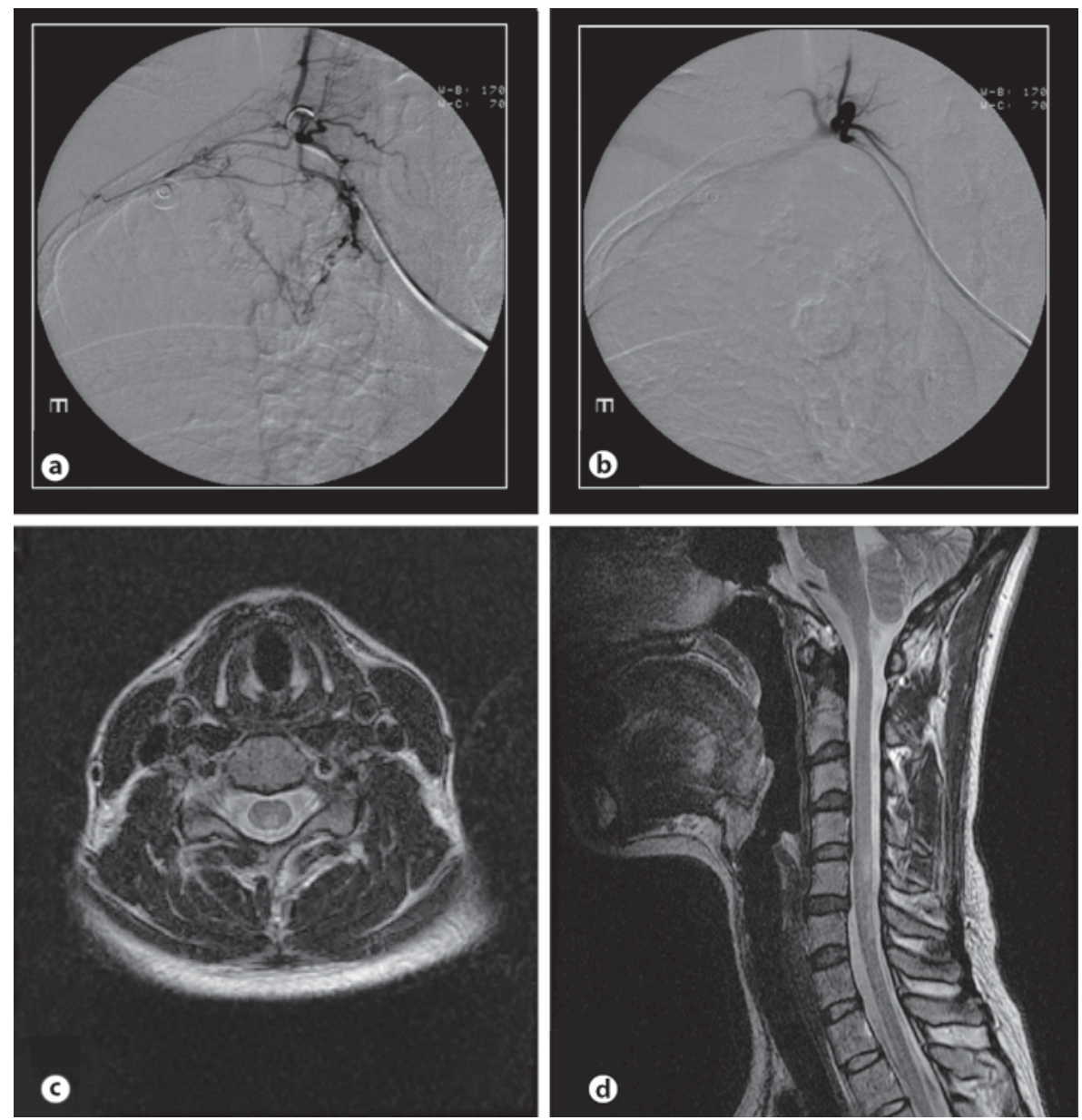

Fig. 1. Thyrocervical angiography showing systemic-pulmonary arterial shunt (a) and regression of parenchymal stain after embolization (b). Axial $\mathrm{T}_{2}$-weighted (c) and sagittal $\mathrm{T}_{2}$-weighted (d) cervical spine MRI showing a high signal lesion in the posterior cervical cord area (C5-7).

\section{KARGER}

Fax +41613061234

E-Mail karger@karger.ch

www.karger.com
(C) 2008 S. Karger AG, Basel

0014-3022/08/0594-0200\$24.50/0

Accessible online at:

www.karger.com/ene
Kwang Soo Lee

Department of Neurology, Kangnam St. Mary's Hospital

505, Banpo-dong, Seocho-gu

Seoul 137-701 (Korea)

Tel.+82 2590 2091,Fax +82 2599 9686, E-Mail ks1007@catholic.ac.k 
lower extremities it was 4+/5 (Medical Research Council's scale). The patient's gait was wide-based and ataxic. Tendon reflexes of the lower extremities were slightly brisk, together with an equivocal extensor plantar response bilaterally. Spinal magnetic resonance imaging (MRI), performed at $4 \mathrm{~h}$ after the onset of symptoms, showed a subtle signal change in the posterior cervical cord (C5-7). Follow-up spinal MRI after 1 week showed more definite high signal change in the previous lesion (fig. 1c, d). The patient was treated with lower molecular heparin and improved significantly after several days.

\section{Discussion}

The spinal cord is supplied by 1 anterior spinal artery (ASA) and 2 posterior spinal arteries (PSA) and, at many levels, they receive a supply from the radicular arteries [5]. The cervical radicular arteries may originate from the vertebral, thyrocervical or costocervical trunk; in the upper six segments they can arise from the vertebral or from the ascending cervical branch of the thyrocervical trunk. A radicular of the 7th or 8 th segment is always from the branches of the costocervical trunk [6]. The PSA is augmented by 10-20 posterior radicular arteries, which are more numerous than the 7-10 arteries of the ASA [7].

Embolotherapy is an important treatment option for patients with massive and recurrent hemoptysis. The most feared complication of embolotherapy is spinal infarction resulting from embolization of a spinal artery $[11,12]$. Most reports about complications of embolotherapy for hemoptysis described anterior spinal cord infarction (ASCI), which may have resulted from occlusion of an ASA feeder [8-12]. Posterior spinal cord infarction (PSCI) is exceedingly rare because of an anastomotic network of direct penetrating vessels and a plexus of pial vessels fed by the paired PSA [3].

In our case, PSCI may be due to occlusion of a singular posterior spinal radicular artery arising in the unilateral thyrocervical trunk, supplying blood to both sides of the spinal cord posteriorly at the C5-7 level.

Angiographically invisible small branches may play an important role in the blood supply to the spinal cord [2]. Furthermore, posterior radicular arteries are smaller than anterior radicular arteries and, because of their size, are difficult to see on angiograms $[13,14]$. Therefore, the occurrence of spinal cord infarction after embolotherapy was not predicted by preliminary angiography and the physician must be more cautious of spinal cord infarction throughout the procedure.

To our knowledge, we believe that this is the first case demonstrating a bilateral cervical PSCI due to unilateral thyrocervical trunk embolizaton for hemoptysis.

\section{References}

1 Sandson TA, Friedman JH: Spinal cord infarction: report of 8 cases and review of the literature. Medicine (Baltimore) 1989;68: 282-292.

2 Cheshire WP, Santos CC, Massey EW, Howard JF Jr: Spinal cord infarction: etiology and outcome. Neurology 1996;47:321-330.

3 Bergqvist CA, Goldberg HI, Thorarensen O, Bird SJ: Posterior cervical cord infarction following vertebral artery dissection. Neurology 1997;48:1112-1115.

4 Weidauer S, Nichtweiss M, Lanfermann H, Zanella FE: Spinal cord infarction: MR imaging and clinical features in 16 cases. Neuroradiology 2002;44:851-857.

5 NovyJ, Carruzzo A, Maeder P, Bogousslavsky J: Spinal cord ischemia. Arch Neurol 2006; 63:1113-1120.
6 Chakravorty BG: Arterial supply of the cervical spinal cord (with special reference to the radicular arteries). Anat Rec 1971;170: 311-329.

7 Gillilan L: The arterial supply of the human spinal cord. J Comp Neurol 1958;110:75100.

8 Wong ML, Szkup P, Hopley M: Percutaneous embolotherapy for life-threatening hemoptysis. Chest 2002;121:95-102.

9 Ramakantan R, Bandekar VG, Gandhi MS, Aulakh BG, Deshmukh HL: Massive hemoptysis due to pulmonary tuberculosis: control with bronchial artery embolization. Radiology 1996;200:691-694.

10 Vujic I, Pyle R, Parker E, Mithoefer J: Control of massive hemoptysis by embolization of intercostal arteries. Radiology 1980;137:617620 .
11 Tonkin IL, Hanissian AS, Boulden TF, Baum SL, Gavant ML, Gold RE, George P, Green WJ: Bronchial arteriography and embolotherapy for hemoptysis in patients with cystic fibrosis. Cardiovasc Intervent Radiol 1991;14:241-246.

12 Cohen MA, Doershuk CF, Stern RC: Bronchial artery embolization to control hemoptysis in cystic fibrosis. Radiology 1990;175: 401-405.

13 Bowen BC, DePrima S, Pattany PM, Marcillo A, Masden P, Qencer RM: MR angiography of normal intradural vessels of the thoracolumbar spine. AJNR 1996;17:483-494.

14 Lasjaunias P, Berenstein A: Spinal and spinal cord arteries and veins; in Lasjaunias $\mathrm{P}, \mathrm{Be}$ renstein A (eds): Surgical Neuroangiography. Berlin, Springer, 1990, vol 3, pp 15-83. 